\title{
Architectural Simulation of the Integration of Building Information Modelling (BIM) \& Business Process Modelling (BPM)
}

\author{
María Eguaras-Martínez, César Martín-Gómez, Marina Vidaurre-Arbizu. \\ School of Architecture. Universidad de Navarra, Pamplona, Spain
}

Thomas Brennan.

BOC Information Technologies Consulting Ltd. Dublín, Ireland.

Stelios Krinidis, Dimosthenis Ioannidis, Dimitrios Tzovaras.

Information Technologies Institute. Center for Research and Technology Hellas, Thessaloniki, Greece.

KEYWORDS: Architecture, Building Information Model (BIM), Business Process Model (BPM), Energy Efficiency, Simulation, Software.

ABSTRACT: The current methods of building energy simulation that designers and engineers (D\&E) use in order to find the energy performance of a building do not take into account the real behavior and daily activities of the people who will use the building. The main aim of this paper is to demonstrate that a system for building simulation, that produces data about the activity behaviour of occupants as members of an enterprise structure and framework, can significantly improve the relevance and performance of building simulation tools, through the study of a real building in daily operation. Furthermore, data (BIM, BPM and occupancy data) has been performed exploiting Open Reference Data Modelling methodology in order to be reusable.

\section{INTRODUCTION}

The idea of business processes has been around for a long time. It was a commonplace term at conferences in the 1930s when people met to discuss how to streamline manufacturing processes. The idea of business processes as a unit of work that begins with a set of inputs and then proceeds to transform those inputs into outputs of value for the business is straightforward.

Moreover, much research effort within EU funded projects as well as international research actions have been devoted to resolve the shortcomings of the current available building simulation and automation programs and respective Building Information Modelling (BIM) approaches.

However, none of these efforts focus on analyzing the overall patterns, semantics and complexity of day-to-day human activity and movement within buildings, as well as the relation of these activities to domain specific enterprise processes governing commercial buildings operation and performance (Chang \& Hong 2013; Zimmermann 2006). A system for building simulation, especially in cases of commercial and mix-used buildings, that produces data about the activity behaviour of occupants as members of an enterprise structure and framework can significantly improve the relevance and performance of building simulation tools (Wang et al. 2011; Page et al. 2008; Virote \& Neves-Silva 2012). This is relevant for engineering domains, like building physics, as well as for architects to analyse and evaluate the performance of a building design
(Clevenger \& Haymaker 2006; Crawley et al. 2001; Crawley et al. 2008).

Furthermore, in cases of constructions of commercial use, the need to treat and balance energy performance with business performance is still ignored. The benefits of reducing power consumption and respective costs, is usually achieved at the expense of critical business services. Business operations (process organization and management) are an inseparable part of overall business services as well as overall enterprise energy consumption. Ideally, energy consumption should be tracked back to spatiotemporal aspects of business operations (Eguaras et al. 2014, Burgeois et al. 2006; Hoes et al. 2009; Lee et al. 2011; Young et al. 2011).

A holistic enterprise modelling and simulation approach should undoubtedly incorporate all levels of business operations, allowing for optimal decisions during early construction design phase. Design decisions on energy performance optimization should be based on sound and realistic estimations of the actual future energy consumption of constructions during operation, taking also into account potential consequences on business operations affected by early design decisions and vice versa.

This special issue presented in this article is a part of the Adapt4EE project whose objective is augmenting the contemporary architectural envelope by incorporating business and occupancy related information thus providing a holistic approach to the design and evaluation of the energy performance of construction products at an early stage and prior to their realization (Hensen 2004; Malavazos et al. 


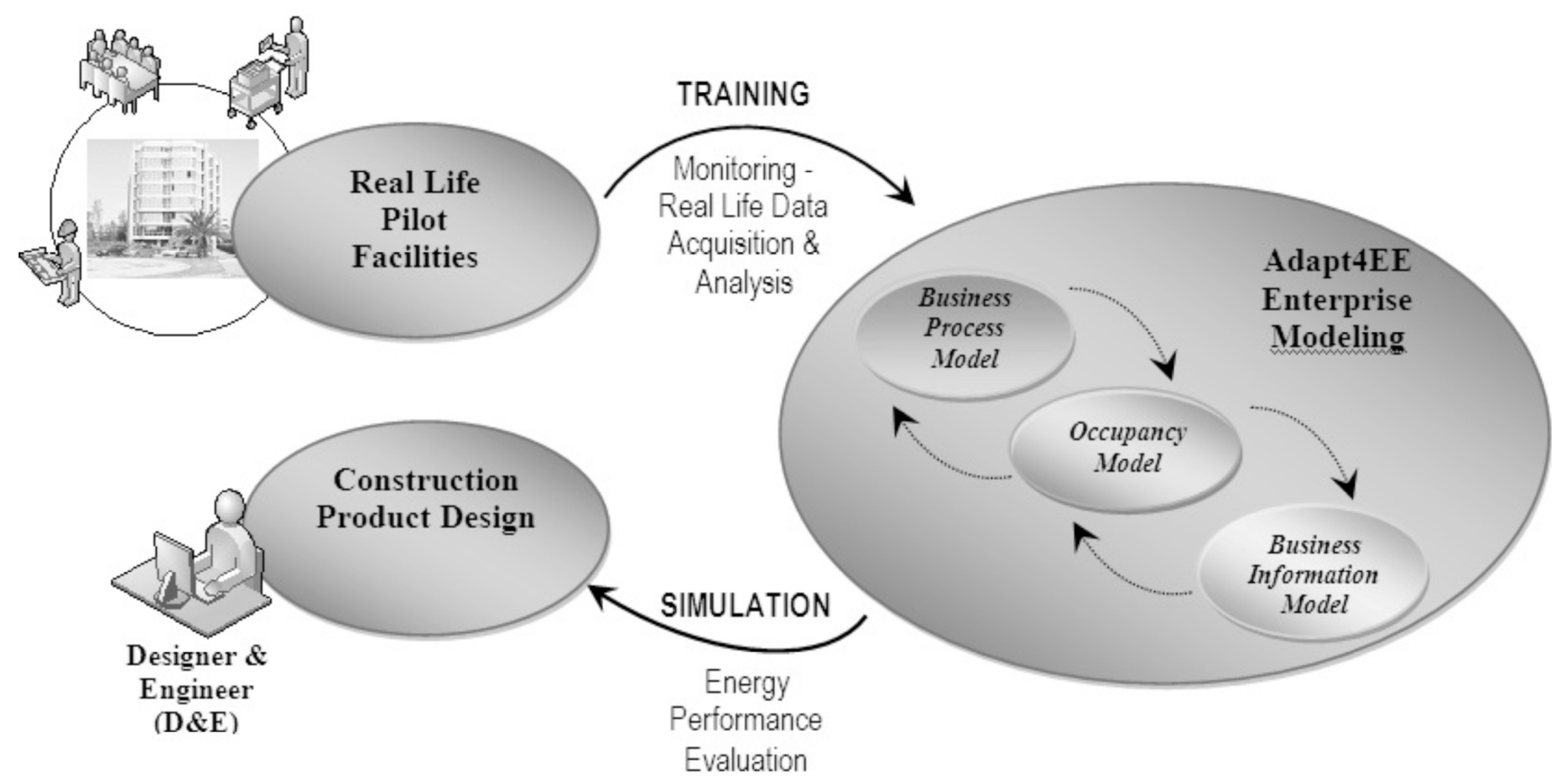

Figure 1. The Adapt4EE Concept.

2011; Ioannidis et al. 2012). The project framework, having as a central point of reference the occupancy behavior (presence and movement) will align energy consumption points to all interrelated enterprise aspects (business processes, enterprise assets and utility state and operations) (Liao \& Barooah 2010; Kashif et al. 2011).

The project aims to develop and validate a holistic energy performance evaluation framework that incorporates architectural metadata (BIM), critical business processes (BPM) and consequent occupant behaviour patterns, enterprise assets and respective operations as well as overall environmental conditions as shown in Figure 1.

The project framework and tools will be thoroughly evaluated in terms of modelling, simulation and energy performance predictive precision, energy gains as well as end user acceptance within two distinct pilot cases, performed on a Hospital in the north of Spain and on a Multipurpose Office/Commercial Building in Portugal.

In order to execute these studies in the framework of the project, one of the pilot sites has been modelled and analyzed in detail. It is a building typology with a mixture of uses that makes it very suitable to carry out this study and extrapolate the results to the wide range of building types. This is a multi-purpose stadium sited in Coimbra, in the west of Portugal, 'Estádio Cidade de Coimbra' (Coimbra Stadium).

\section{METHODS}

\subsection{General Approach}

The proposed framework consists of a variety of tasks. The daily business processes and the activities that are comprised of should be detailed recorded, analysed and modelled following a top-down approach (Benezeth at al. 2011). The approach selected allows also for an instance-level research by investigating into the business activities and actual exexecution trails, following an abstraction approach (Bourgeois et al. 2004; Bourgeois et al. 2006; Lam et al. 2009). For the pilot, a workshop-driven topdown information acquisition process was applied, extracting the desired information of all business processes and their activities concerning their execution within the scope of the project (Ioannidis et al. 2012; Ioannidis et al. 2014).

Furthermore, the modelling methodology of business processes and the business activities that are comprised of, should require a hybrid metamodelling approach. The integrated activity model consists of the location that is occurred, the roles that are involved in the activity, the equipment/resources (type, location, etc.) that are used to support it, and the activities interaction and interconnection with other activities (Dong \& Andrews 2009; Duarte et al. 2013; Hutchins et al. 2007; Dong et al. 2010).

Simulation of the business processes (BPM) activities occurring in a building (BIM) is able to produce detailed information about the occupancy of the desired building architecture model. It can produce the occupants' movements through the building's spaces based on the execution of the daily business processes' activities and the equip- 
ment/resources involved, and as a consequence the occupancy of each space. Furthermore, the simulation should additionally provide information about the energy consumption of the building based on the occupancy of each space and the equipment/resources used by the business processes' activities (Page 2007; Mahdavi \& Pröglhöf 2009; Li et al. 2012). The connection and the correlation of the energy consumption of a building with the business processes occurring in it should deliver accurate simulation results of the building's occupancy and its energy consumption.

\subsection{OpenStudio software tool}

The Building Information Modelling (BIM) OpenStudio cross-platform (Windows, Mac, and Linux) software tool was chosen as the tool to support the building information modelling activities of the pilot case analysed under this research. This collection of tools support whole building energy modelling using EnergyPlus. This is a whole building information program that engineers, architects, and researchers use to model energy and water use in buildings.

The main strength of OpenStudio is that it is a free tool that is part of an open source project to facilitate community development, extension, and private sector adoption. The OpenStudio graphical applications include the SketchUp Plug-in (that allows users to quickly create geometry and assign space attributes using the built-in functionality), the stand alone OpenStudio application, and ResultsViewer. It is a graphic energy modelling tool and includes visualization and editing of schedules, editing of loads constructions and materials, a drag and drop interface to apply resources to spaces and zones, a visual HVAC and service water heating design tool, and high level results visualization. OpenStudio also gives the modeler-integrated access to data from the Building Component Library. ResultsViewer enables browsing, plotting, and comparing EnergyPlus output time series data. It allows building researchers and software developers to quickly get started through its multiple entry points, including access through $\mathrm{C}++$, Ruby, and C\#.

\subsection{ADONIS Business Process Management Toolkit}

To perform the Business Process Modelling (BPM) of the pilot site, the ADONIS software tool has been chosen. ADONIS is a key part of the BOC Management Office. This is a comprehensive tool suite that supports the introduction and implementation of standardised management approaches. ADONIS is the flagship product and it supports the core activities of BPM methodologies including information acquisition, modelling and design, analysis, simulation and evaluation.
The key design aspects that were taken into account were the usability of the software and its openness, method flexibility and metamodelling capabilities. ADONIS supports standard modelling languages such as BPMN, UML, EPC, and LOVEM (List \& Korherr 2006). In addition, ADONIS provides an underlying meta modelling technology that allows users to define new modelling languages and mechanisms for domain-specific or customer-specific needs as presented in Figure 2.

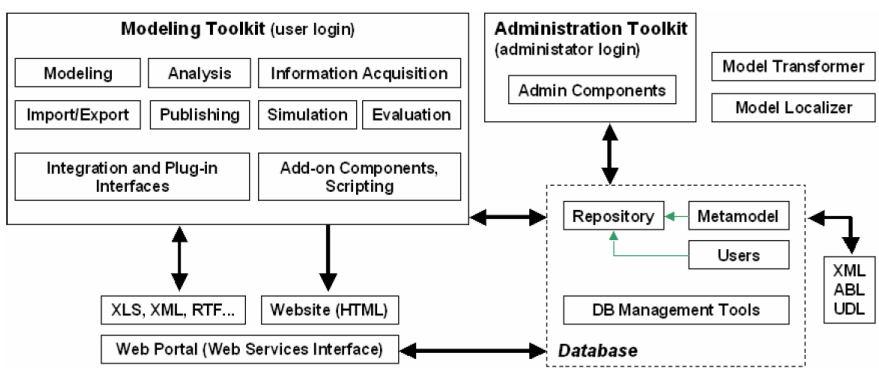

Figure 2. Overview of the ADONIS Architecture.

The following considerations have been made in context of the BPM approach in the Adapt4EE project:

- Hybrid BPM approach: since the results do not only focus on process models but aim at integrating views from different backgrounds, a tool that supports the modelling of BPs, organisational structures, resources, locations, etc. is needed.

- Formalisation of outputs: The output of the BPM task must be machine interpretable. Hence a pure "drawing" approach was not sufficient for the project.

- Extendibility: in relation to the hybrid combination approach, a means to extend, modify, update the underlying meta-model is needed to reflect domain-specific concepts but also ease the development process of models and metamodels.

- Pre-existing solution/Industry-approved: the ADONIS tool selected is well-established in the BPM industry.

\subsection{Pilot Site: 'Estádio Cidade de Coimbra'}

The pilot site studied in this research is the 'Estádio Cidade de Coimbra' (Coimbra Stadium), a multipurpose stadium that currently supports multiple uses:

- Sports Events. It is the home stadium of one of the teams of the Portuguese premium football league (AAC - Associaçào Académica de Coimbra) hosting 25-35 football games per year. It is also a regular training and competing facility for Athletic sports. 
- Entertainment. The stadium also houses other events, such as music concerts, religious events and exhibitions.

- Regular commercial and office use. The stadium includes a large number of commercial and office spaces, which are rented to more than 20 tenants. Some spaces are exclusively used for such purposes, while others have dual use: they support large sport and cultural events and they are used, during the rest of the time as business spaces.

- Underground parking for both private and public (paid) use.

It has been selected based on the following principles: it constitutes a commercial building with mutifaceted areas and operations, consisting of subareas with well defined everyday business operations highly correlated to specific "business" services, respective business episodes and occupancy patterns. It also belongs to commercial domains of great importance and difficulty for the D\&E Industry. In this case, real enterprise data will be acquired, monitored and analyzed concerning the actual space utilization and respective business scenarios in order to train and calibrate the project simulation models accordingly.

The stadium was recently rebuilt, expanded and modernized (2003) to host some UEFA Euro 2004. Nevertheless, the energy infrastructure of the building was not conceived for its current usage model.

Its design does not involve any historical or traditional references, as the idea was to create a new, contemporary image with glass façades and an aesthetic roof supported by elegant stands. The existing athletics track has been preserved for possible use as a multi-purpose facility in the future. The Portuguese architectural firm Plarq in association with KSS Design Group of London designed the stadium. In Figure 3 the magnitude of the Stadium is shown.

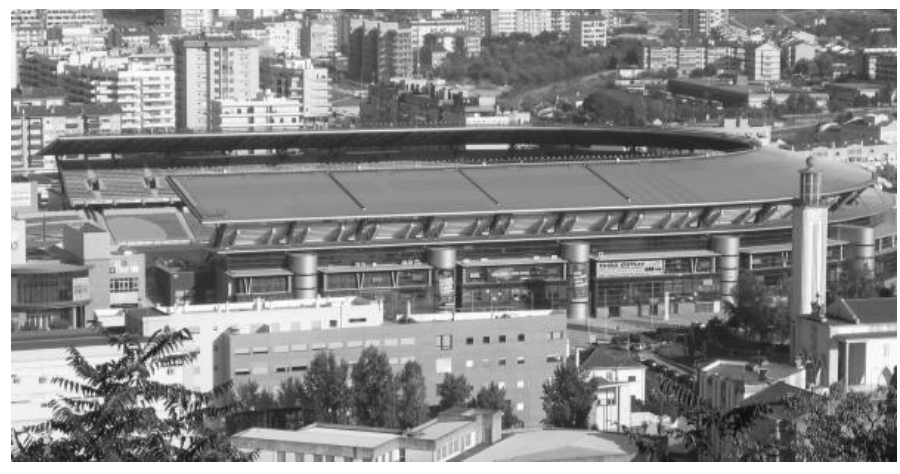

Figure 3. External view of the Coimbra Stadium.

Since this is a complex building, several areas have been selected to model instead of the whole building, while trying to reflect the mixed of uses of the building.
In applying the BPM procedural approach at the pilot site we firstly had to analyse the building plans to identify the departments and occupants who would be involved in the process discovery activities.

The plan that was considered was the plan of the ISA offices (a project partner) as shown in Figure 4 below. It is an open plan office environment and the process area we focused on for the project was the procurement department.

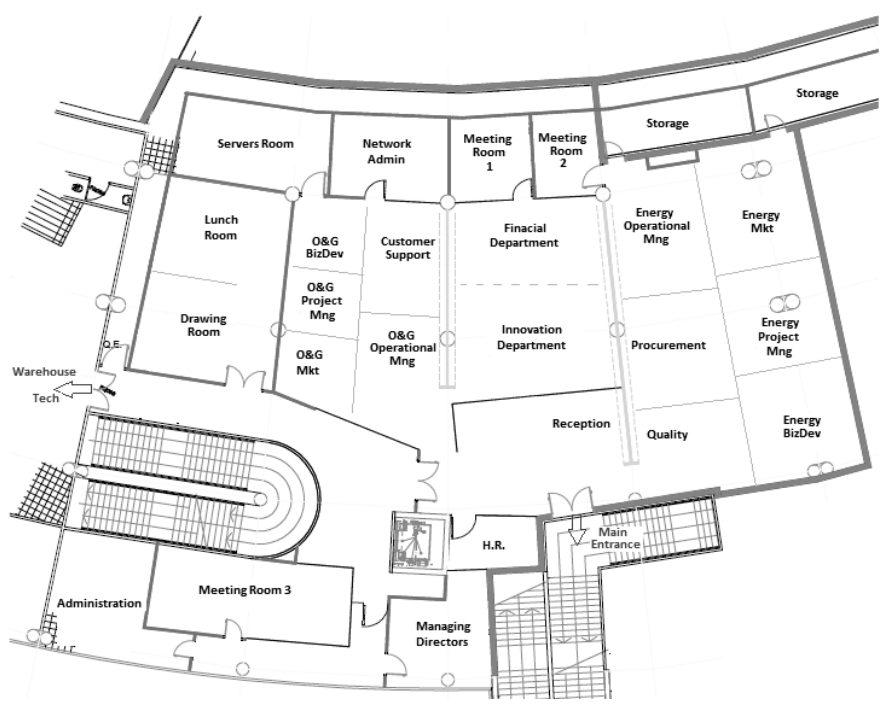

Figure 4. ISA Main Area, selected as pilot area.

This area has been proposed as pilot area because the different roles in the ISA company use this area and could be study as a scale laboratory in order to reflect the mixture of uses that are given in the building: reception, meeting rooms, financial department, restrooms, storage areas, working departments. The selected area studied in this project has around 1.200 square meters and has over $80-90$ occupants.

During the preparation phase of the model, all the information has been gathered asking the different roles that perform their activity in the area selected, resulting in a large number of interviews with the ISA staff.

\section{ARCHITECTURAL SIMULATION}

\subsection{Building Information Models Results (BIM)}

Three modelling options have been made for the purpose of comparing simulation results, with the options that a designer could have in the beginning of the design process:

- The use of template data provided by OpenStudio software. In this case the Medium Office template has been used. The templates in OpenStudio are designed for specific building types 
and are loaded with construction, schedule, and internal load data for various time-periods. These templates can be customized to meet the designer needs.

- The data derived from occupant's interviews. This is a more real simulation made with the data gathered using the Business Process Models (BPM) made within the EU project, and the actual data of loads (people, schedules, type of lights, number and type of equipment).

- The data provided by the Adapt4ee system architecture (data acquired by the sensors installed in the pilot site).

During the training phase of the Adapt4EE project a representative set of sensors has been installed in each pilot and linked with the pilot models used by Adapt4EE, feeding the platform with the first datasets of collected measurements. This set of sensors is made up depth sensors, energy consumption meters, RFIDs and air quality sensors.

Besides, a backbone infrastructure for hosting the sensors has been deployed in each of the pilots, supporting future expansion work.

The data of sensors installed in this area were extracted and analysed for one week (11/18 to 11/24). The simulation run was made for the same period.

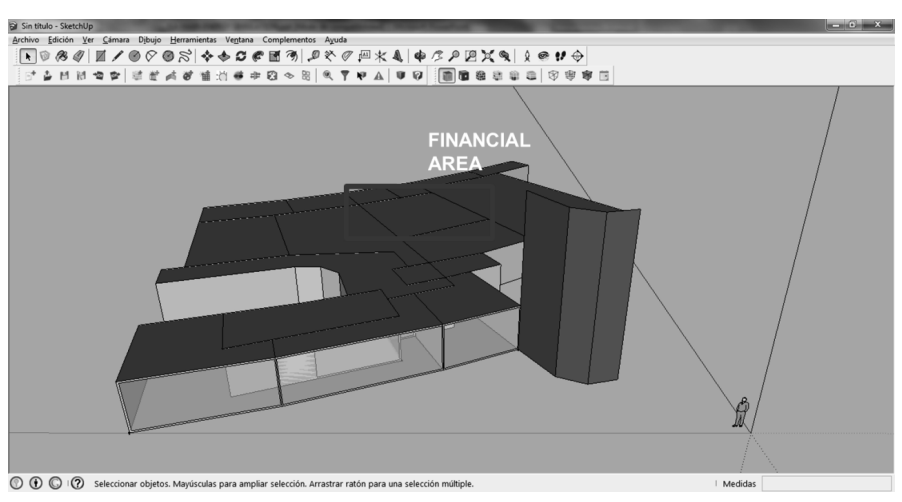

Figure 5. OpenStudio picture that represents the ISA model.

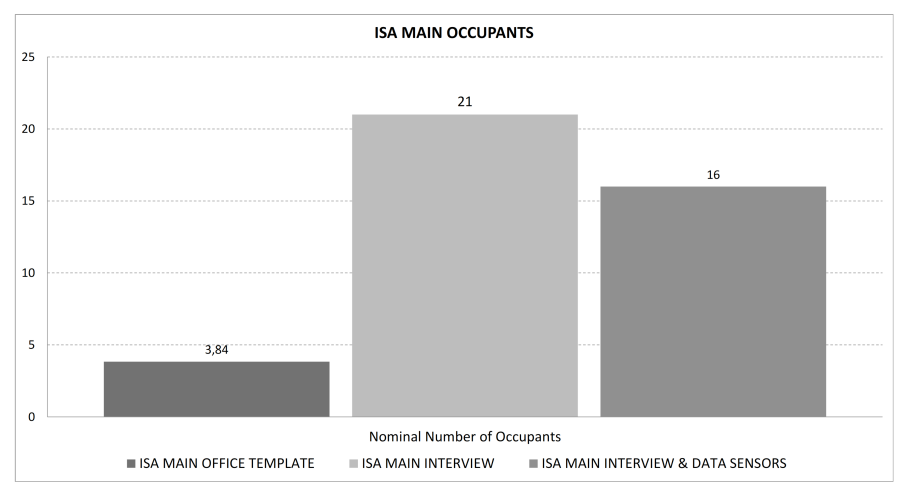

Figure 6. Data of occupants extracted of each of the models performed.
As a result, for this area, several models have been performed using the different modelling options; one of the models (the financial department area), in which this study is based, is shown in Figure 5.

The first differences found are regarding the occupancy of the spaces, not only in number of occupants but also in the schedule they follow. These differences are shown in Figures 6 and 7.

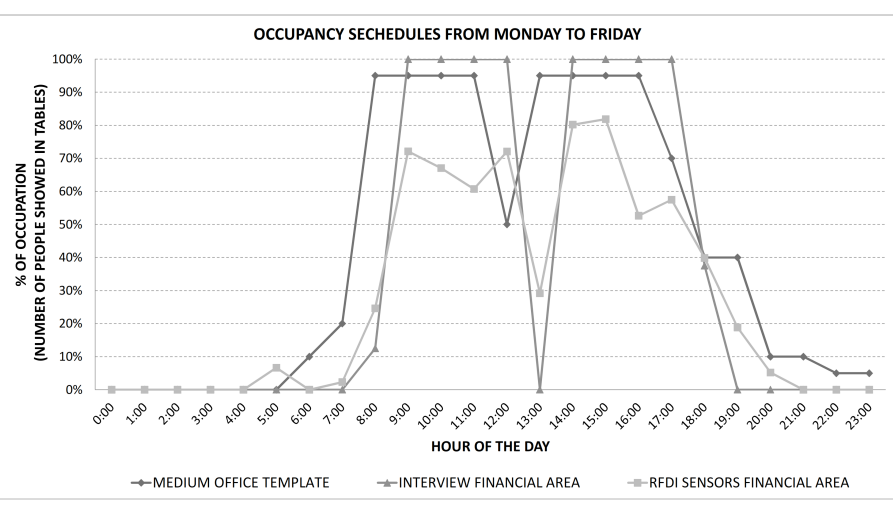

Figure 7. Occupation schedules from Monday to Friday of each of the models performed.

Obviously there are also differences among the loads (occupation, lights, electric equipment) considered in each of the situations.

\begin{tabular}{cccc}
\hline $\begin{array}{c}\text { Financial area } \\
71,34 \mathrm{~m} 2\end{array}$ & $\begin{array}{r}\text { Lighting } \\
{[\mathrm{W} / \mathrm{m} 2]}\end{array}$ & $\begin{array}{c}\text { People } \\
{[\mathrm{m} 2 / \text { person }]}\end{array}$ & $\begin{array}{r}\text { Equipment } \\
{[\mathrm{W} / \mathrm{m} 2]}\end{array}$ \\
\hline Office Template & 9,69 & 18,58 & 5,81 \\
Interviews & 7,06 & 3,40 & 15,84 \\
Data sensors & 7,06 & 4,46 & 15,84 \\
\hline
\end{tabular}

Figure 8. Figure that shows the differences among the loads.

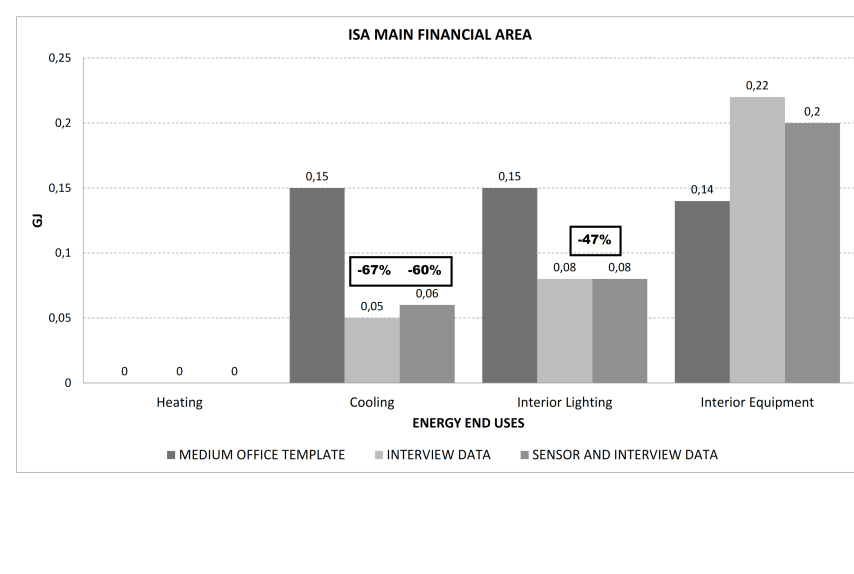

Figure 9. Energy for heating, cooling, interior lighting and interior equipment in each of the simulations. 
The simulation results can be seen in the following graphs. The simulations made with data of occupancy extracted by sensors show small differences with the ones made with data from interviews.

The mentioned simulations show high differences (up to $67 \%$ ) with the ones made with the Medium Office Template provided by OpenStudio.

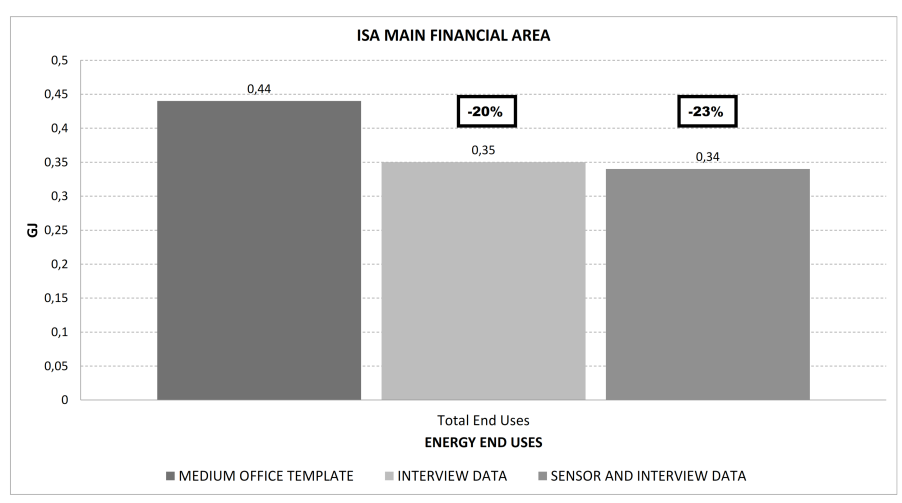

Figure 10. Energy end uses for each of the simulations.

\subsection{Business Process ISA Model}

The detailed business processes at ISA were modelled by following the procedural model as mentioned above. Before the results of the initial modelling efforts could be used in the Adapt4EE simulation environment the detailed business processes needed to be converted into skeleton activity models. Further activity classification was performed to identify the business and non-business activities. Non-business activities are ad-hoc or unplanned activities that the occupants of the ISA office could perform at any time of the day.

In order to extract the skeleton activities from the detailed business process models, we first had to identify, in the detailed business process models, the attributes and parameters of the activities that could be captured using the sensor layer of the Adapt4EE measurement framework.

The parameters of the activities of the detailed business process models that relate to the evidence captured by the sensors were:

- The type of space where the activity takes place.

- The actors involved.

- The type and intensity of resources used and

- The environmental conditions of the space.

Based on these parameters we aggregated the activities that produce the same expected evidence, into one skeleton activity. A series of heuristics were applied to the detailed business processes in order to extract the skeleton activity models. They included the following analysis to reduce the complexity in the models and to assist in the collection of evidence related to individual activity instances:
- If an activity or a series of activities is being performed by the same role in the same location (e.g. - cleaning patient cubicle), Figure 11.

- If an activity or a series of activities is being performed by more than one role in the same location then it is considered to be a collaborative activity (e.g. - a meeting or presentation).

- If an activity or series of activities is being performed by the same role in the same location using the same resource(s) (e.g. - Printing letter).

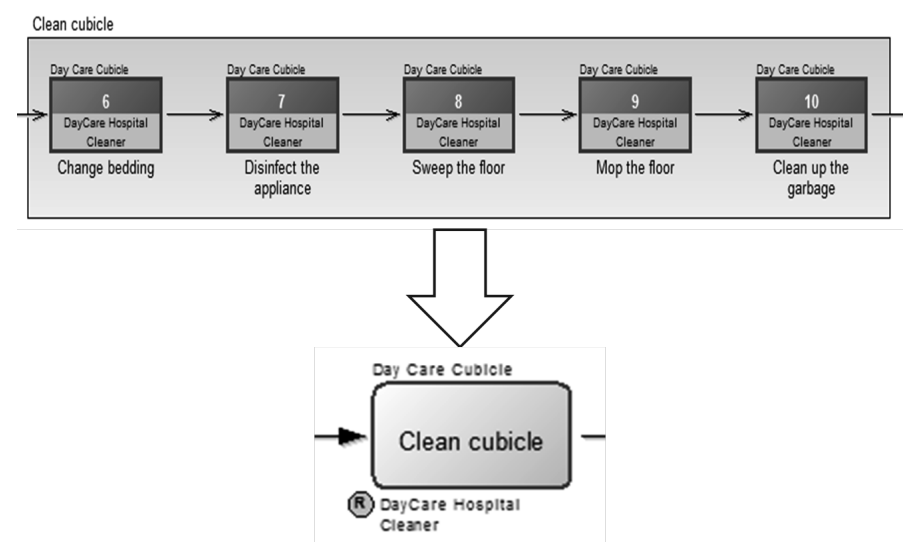

Figure 11. Overview of an activity modelled with ADONIS.

Before the skeleton activity models could be used by the Adapt4ee simulation environment they needed to be exported from the ADONIS tool in an XML format that was aligned to the Common Information Model (CIM).

The CIM was used to describe the information sources that are used by modules of both measurement and simulation frameworks of Adapt4EE system. The CIM enabled the integration of the information about Buildings, Business processes as well as High-level events from the middleware used (Events about occupancy, devices and sensor measurements) in the measurement phase as well as results from agent simulation in the simulation phase.

The agent based simulation framework was then able to take the exported skeleton activity models in the CIM aligned XML format and perform process mining of the events perceived during the measurement phase and the skeleton activity models were subsequently enriched with updated timings and occurrence patterns.

\section{DISCUSSION}

The focus of the paper at hand is to describe the methodology applied to enrich Building Information Models (BIM) with Business Process Models (BPM) from the perspective of business process management systems. With this combination the accuracy and value of the simulation can be enhanced since 
not only static average data is applied during the simulation runs, but also real data gathered from the Adapt4EE system architecture are include in them. As this is a part of an ongoing project, the preliminary results shows above, obtained in a first version of the occupancy training system developed, in the absence of a more detailed study that covers the full period of one year, show different results that can be analyzed.

One of the main conclusions of this study is that it is possible to save a great amount of energy and therefore money, by merely taking into account the result of using business processes taken from the day-today activities of the pilot domains. This energy savings could be extrapolated to other mixed-used buildings by the fusion of two (currently separate) worlds: Building Information Modelling (BIM) and Business Process Modelling (BPM), with the occupants as main catalyst.

\section{Acknowledgements}

This research has been made according to 'Occupant Aware, Intelligent and Adaptive Enterprises', Adapt4EE project, co-funded by the European Commission within the $7^{\text {th }}$ Framework Program (FP7/2007-2013) under the Grant Agreement no 288150. We kindly acknowledge the support of the European Commission and the project partners.

\section{REFERENCES}

- Attia S, Gratia E, De Herde A, Hensen J. L.M. Simulationbased decision support tool for early stages of zero-energy building design, Energy and Buildings 49 (0), pp. 2-15, 2012.

- Benezeth Y, Laurent H, Emile B, Rosenberg C. Towards a sensor for detecting human presence and characterizing activity, Energy and Building 3, pp. 305-314, 2011.

- Bourgeois D, Reinhart C.F, Hand J, MacDonald I. Adding sub-hourly occupancy prediction,occupancy-sensing control and manual environmental control to whole-building energy simulation. Proceedings of the CIB World Building Congress 2004, Toronto, Canada, May 2004, p. 8, 2004.

- Bourgeois D, Reinhart C, and Macdonald I. Adding advanced behavioural models in whole building energy simulation: A study on the total energy impact of manual and automated lighting control, Energy and Buildings Vol. 38, pp. 814-823, 2006.

- Chang W, Hong T. Statistical Analysis and Modelling of Occupancy Patterns in Open-Plan Offices using Measured Lighting-Switch Data. Ernest Orlando Lawrence Berkeley National Laboratory, January 2013.

- Clevenger C, Haymaker J. The Impact of the Building Occupant on Energy Modelling Simulations, Joint Internation- al Conference on Computing and Decision Making in Civil and Building Engineering, 2006, Montreal, Canada.

- Crawley D, Lawrie B, Winkelmann L.K, Buhl F.C, Huang W.F, Pedersen Y.J, Strand C.O, Liesen R.K, Fisher R.J, Witte D.E, Glazer M.J and J. EnergyPlus: creating a newgeneration building energy simulation program. Energy and buildings 2001. 33 (4):319-331.

- Crawley D.B, Hand J.W, Kummert M, Griffith B.T. Contrasting the capabilities of building energy performance simulation programs. Building and Environment 2008; 43(4):661-73.

- Dong B, Andrews B. Sensor based occupancy behaviour pattern recognition for energy and comfort management in intelligent buildings, 11th International Building Performance Simulation Association (IBPSA) Conference, 2009.

- Dong B, Andrews B, Poh Lam K, Hoynck M, Zhang R, Chiou Y, Benitez D. An information technology enabled sustainability test-bed (ITEST) for occupancy detection through an environmental sensing network, Energy and Buildings, Volume 42, Issue 7, pp 1038-1046, 2010.

- Duarte C, Van Den Wymelenberg K, Rieger C. Revealing occupancy patterns in an office building through the use of occupancy sensor data, Energy and Buildings 67, pp. 587595, 2013.

- Eguaras M, Martín-Gómez C, Vidaurre, M. Simulation and evaluation of Building Information Modelling in a real pilot site. Applied Energy 114 (2014) 475-484. ISSN 03062619. DOI: $10.1016 /$ j.apenergy.2013.09.047.

- Hensen J.L.M. Towards more effective use of building performance simulation in design. Developments in Design \& Decision Support Systems in Architecture and Urban Planning, 2004:291-306. Eindhoven, the Netherlands.

- Hoes P, Hensen j.L.M, Loomans M.G.L.C, de Vries B, Buourgeois D. User behaviour in whole building simulation. Energy and Buildings 41 (3), pp. 295-302, 2009.

- Hutchins J, Ihler A, Smyth P. Modelling count data from multiple sensors: a building occupancy model, IEEE International Workshop on Computational Advances in MultiSensor Adaptive Processing, December 2007.

- Ioannidis D, Tzovaras D, Malavazos C. Occupancy and Business Modelling. 9th European conference on product and process modelling. (ECPPM 2012), 3rd Workshop on eeBDM, eeBIM, Reykjavik, Iceland. 2012.

- Ioannidis D, Krinidis S, Stavropoulos G, Tzovaras D, Likothanassis S. Full-automated acquisition system for occupancy and energy measurement data extraction, Symposium on Simulation for Architecture and Urban Design (simAUD'14), pp. 165-172, Tampa, FL, USA, 2014.

- Kashif A, Binh Le H, Dugdale J, Ploix S. Agent based framework to simulate inhabitants'behaviour in domestic settings for energy management. ICAART 2011 (International Conference on Agents and Artificial Intelligence), Rome, Italy, January 2011.

- Lam K. P, Höynck M, Zhang R, Andrews B, Chiou Y.S, Dong B, Benitez D. Information-theoretic environmental features selection for occupancy detection in open offices, Proceedings of Building Simulation 2009, Glasgow, 2009.

- Lee Y.S, Yi Y.K, Malkawi A. Simulating human behaviour and its impact on energy uses. Presented at the 12th Con- 
ference of International Building Performance Simulation Association, Sidney, Australia, 2011.

- Li N, Calis G, Becerik-Gerber B. Measuring and monitoring occupancy with and RFID based system for demanddriven HVAC operations, Automation in Construction 24, pp. 89-99, 2012.

- Liao C, Barooah P. An integrated approach to occupancy modelling and estimation in commercial buildings, Proc. American Control Conf. (ACC), pp. 3130-3135, 2010.

- List B, Korherr B. An evaluation of conceptual business process modelling languages, Proceedings of the 2006 ACM symposium on Applied computing, ACM, pp. 1532 1539, 2006.

- Mahdavi A, Pröglhöf C. Toward empirically based models of people's presence and actions in buildings, Proceedings of Building Simulation, Scotland 9, pp. 537-544, 2009.

- Malavazos C, Ioannidis D, Kehagias D, Tzovaras D. Energy and behavioural modelling and simulation for EEbuilding design. $2^{\text {nd }}$ Workshop eeBuilding Data Models. Sophia Antipolis, France, 2011.

- Malavazos, C et al. Activity based \& behavioural occupancy modelling for EE building design. Revista de Edificación, 41-42, 2013.

- Page J. Simulating occupant presence and behaviour in buildings. École polytechnique fédérale de Laussane, Lausanne, Switzerland. 2007.

- Page J, Robinson D, Morel N, Scartezzini J. L. A generalised stochastic model for the simulation of occupant presence, Energy and Building 40 (2), pp. 83-98, 2008.

- Sánchez, Tengori, Favela. Activity recognition for the smart hospital, IEEE Computer Society, 1541-1672/08, 2008.

- Tabak V. User simulation of space utilisation: System for office building usage simulation. Ph. D. diss, Eindhoven University of Technology, Netherlands, 2008.

- Tabak V, de Vries B, Dijkstra J. Simulation and validation of human movement in building spaces, Environment and Planning B: Planning and Design 37 (4), pp. 592-609, 2010.

- Virote J, Neves-Silva R. Stochastic models for building energy prediction based on occupant behaviour assessment, Energy and Buildings 53 (0), pp. 183-193, 2012.

- Wang C, Yan D, Jiang Y. A novel approach for building occupancy simulation, Building Simulation 4, pp. 149-167, 2011.

- Young Yun G, Joo Kong H, Tai Kim J. A field survey of occupancy and air-conditioner use patterns in open plan offices. Indoor and Built Environment 20 (1), pp. 137-147, 2011.

- Zimmermann G. Modelling and simulation of dynamic user behaviour in buildings - a lighting control case study", eWork and eBusiness in architecture, engineering and construction: Proceedings of the 6th European conference on product and process modelling. 2006, p. 309-316, Taylor \& Francis Group.

- http://www.adapt4ee.eu/adapt4ee/http://www.bocgroup.com/products/adonis/

- ADONIS ${ }^{\circledR}$ toolkit: al.com/jumpto.jsp?goto=ADONIS\&lg=at
- Business Process Model and Notation (BPMN) Version 2.0, June 2010, OMG Document Number: dtc/2010-06-06, OMG Adopted Beta Specification, 2010. 